\title{
Dynamic changes of oligomeric amyloid $\beta$ levels in plasma induced by spiked synthetic $A \beta_{42}$
}

\author{
Seong Soo A. An ${ }^{1 \dagger}$, Byoung-sub Lee ${ }^{2 \dagger}$, Ji Sun Yu², Kuntaek Lim², Gwang Je Kim², Ryan Lee², Shinwon Kim² ${ }^{2}$, \\ Sungmin Kang ${ }^{2}$, Young Ho Park ${ }^{3}$, Min Jeong Wang ${ }^{3}$, Young Soon Yang ${ }^{4}$, Young Chul Youn ${ }^{5}$ and SangYun Kim ${ }^{3 *}$
}

\begin{abstract}
Background: A reliable blood-based assay is required to properly diagnose and monitor Alzheimer's disease (AD). Many attempts have been made to develop such a diagnostic tool by measuring amyloid- $\beta$ oligomers (AßOs) in the blood, but none have been successful in terms of method reliability. We present a multimer detection system (MDS), initially developed for the detection of prion oligomers in the blood, to detect $A \beta O$ s.
\end{abstract}

Methods: To characterize $A \beta$ in the blood, plasma was spiked with synthetic amyloid- $\beta$ (A $\beta$ ) and incubated over time. Then, the MDS was used to monitor the dynamic changes of A $\beta O$ levels in the plasma.

Results: Increasing concentrations of ABOs were observed in the plasma of patients with AD but not in the plasma of normal control subjects. The plasma from patients with $\mathrm{AD}(n=27)$ was differentiated from that of the agematched normal control subjects $(n=144)$ with a sensitivity of $83.3 \%$ and a specificity of $90.0 \%$.

Conclusions: Synthetic $A \beta$ spiked into the blood plasma of patients with $A D$, but that of not elderly normal control subjects, induced dynamic changes in the formation of $A \beta O$ s over time. A $B O$ s were detected by the MDS, which is a useful blood-based assay with high sensitivity and specificity for AD diagnosis.

Keywords: Multimer detection system, Alzheimer's disease, Amyloid- $\beta$, Oligomers, Blood biomarker, Synthetic amyloid- $\beta$, ELISA, Plasma test

\section{Background}

Amyloid- $\beta(A \beta)$ is a major factor in the pathogenesis of Alzheimer's disease $(\mathrm{AD})[1-3]$. $A \beta$ may be involved in the cognitive impairment of memory that leads to $\mathrm{AD}$, particularly in the form of aggregated 42-amino acid isoform of the $A \beta$ peptide $\left(A \beta_{42}\right)$, which is a major neurotoxic species among $A \beta$ isomers, including $A \beta_{40}, A \beta_{42}$, and other truncated forms of $A \beta[4-10]$. Since the initial identification of these $A \beta$ isomers in bodily fluids, the measurement of $A \beta$ levels in the blood and cerebrospinal fluid (CSF) has been a research priority $[11,12]$. Three biomarkers in CSF, specifically $\mathrm{A} \beta_{42}$, total tau, and hyperphosphorylated tau, are

\footnotetext{
* Correspondence: neuroksy@snu.ac.kr

${ }^{\dagger}$ Equal contributors

${ }^{3}$ Department of Neurology, Seoul National University College of Medicine \& Neurocognitive Behavior Center, Seoul National University Bundang Hospital, 300 Gumidong, Bundang-gu, Seongnam-si, Gyeonggi-do 463-707, Republic of Korea

Full list of author information is available at the end of the article
}

widely accepted as $\mathrm{AD}$ determinants on the basis of their close correlations with AD pathology [13, 14]. Diagnostic imaging using positron emission tomography (PET) is the preferred method of investigating pathological and functional changes in the brain of patient with $\mathrm{AD} .{ }^{11} \mathrm{C}$ - or ${ }^{18}$ F-labeled Pittsburgh compound B-positron emission tomography (PiB-PET), which involves binding to amyloid depositions, is particularly beneficial for understanding the underlying processes of $\mathrm{AD}$. Therefore, this type of imaging is used both in research and in the clinic to differentiate patients with AD from control subjects and individuals with other types of dementia [15-17].

Several noninvasive diagnostics for $\mathrm{AD}$, based on diverse biomarkers in the saliva, urine, and blood, have been reported and are still in the research phase of development [18-21]. Mapstone et al. [22] identified a panel of ten plasma phospholipids as potential diagnostic biomarkers of $\mathrm{AD}$, which included lysophosphatidylcholine, phosphatidylcholine 
metabolites, and acylcarnitine metabolites. This plasma lipid panel predicted AD conversion, suggesting 90\% sensitivity and $85 \%$ specificity in differentiating an at-risk group from the cognitively intact group. Despite encouraging results, low positive predictive values limited the clinical usefulness of this panel as a screening tool in subjects aged 70-80 years or younger. In another study, significant differences in soluble CD40 (sCD40) and sCD40 ligand (sCD40L) levels in plasma were observed between $\mathrm{AD}$ cases and control subjects. sCD40 was approximately three times higher in patients with $\mathrm{AD}$ than in control subjects with sensitivity and specificity of $68 \%$ and $84 \%$, respectively. Similarly, concentrations of SCD40L were 2.27 times higher in $\mathrm{AD}$ cases than in control subjects with sensitivity and specificity of 51\% and $76 \%$, respectively [23]. A biomarker panel of cortisol, pancreatic polypeptide, insulin-like growth factor binding protein 2 , $\beta_{2}$-microglobulin, vascular cell adhesion molecule 1 , carcinoembryonic antigen, matrix metalloproteinase 2, CD40, macrophage inflammatory protein $1 \alpha$, superoxide dismutase, and homocysteine was shown to significantly increase in plasma from patients with $\mathrm{AD}$. In addition, apolipoprotein $\mathrm{E}$ (ApoE), epidermal growth factor receptor, hemoglobin, calcium, zinc, interleukin (IL)-17, and albumin were revealed to be decreased in patients with AD. Cross-validated accuracy measures from the Australian Imaging, Biomarker \& Lifestyle Flagship Study of Ageing (AIBL) cohort reached a mean (SD) of $85 \%(3.0 \%)$ for sensitivity and specificity and 93\% (3.0) for the AUROC. A second validation using the Alzheimer's Disease Neuroimaging Initiative cohort showed accuracy measures of $80 \%$ (3.0\%) for sensitivity and specificity and 85\% (3.0) for the AUROC [24]. Eighteen signaling blood proteins in hematopoiesis, immune responses, apoptosis, and neuronal supports were suggested to differentiate patients with $\mathrm{AD}$ from control subjects with close to $90 \%$ accuracy and also to identify patients who would convert from mild cognitive impairment to AD 2-6 years later [25].

Among these, methods employing blood-based biomarkers have been focused on the detection of amyloid- $\beta$ oligomers (A $\mathrm{BOs})$ and other surrogate biomarkers of $\mathrm{AD}$ [26-31]. Experimental cross-sectional analyses undertaken to detect $\mathrm{A} \beta \mathrm{O}$ s in the plasma have demonstrated limited and inconclusive results [26-28]. Other blood-based surrogate biomarkers, including ApoE, inflammatory markers (IL-8, IL-1a), A $\beta$ autoantibodies, total serum cholesterol, and microRNAs (specifically miR-9, miR-29a, miR-29b, miR101, miR-125b, miR-132, miR-134, and miR-181c), have also demonstrated variability as disease correlates [29-31]. Although there have been difficulties in developing methods for $\mathrm{AD}$ diagnosis using blood-based biomarkers, a reliable and reproducible blood-based assay is still needed for clinical use [32].

A multimer detection system (MDS) was originally developed to detect prion oligomers in the blood of scrapieinfected animals. MDS is a sandwich enzyme-linked immunosorbent assay (ELISA) that preferentially detects oligomers over monomers by creating steric hindrance between capturing and detection antibodies that are specific to a unique/overlapping epitope [33].

In the present study, MDS for AD was developed to detect $A \beta O$ s using two different antibodies against the $\mathrm{N}$ terminus of $A \beta$. Initially, MDS was unable to differentiate $\mathrm{A} \beta \mathrm{O}$ s in the blood of patients with $\mathrm{AD}$ from those of normal control subjects. Synthetic A $\beta$ was then spiked into the plasma of patients with $\mathrm{AD}$ and control subjects. Using MDS, the dynamic changes of $\mathrm{A} \beta \mathrm{O}$ formation were detected in the spiked plasma of patients with $\mathrm{AD}$ but not in the spiked plasma of control subjects. Therefore, in this study, we evaluated the dynamic changes of $\mathrm{A} \beta \mathrm{O}$ levels in the plasma of patients with $\mathrm{AD}$ compared with those of normal age-matched control subjects.

\section{Methods \\ Clinical data}

This study was approved by the institutional review board of Seoul National University Bundang and Chung-Ang University Hospital [B-0905-075-003, B-1202-145-003, C2012048(743), C2013142(1102)]. Pooled plasma samples were collected from 11 patients with $\mathrm{AD}$ and 9 elderly normal control subjects, and individual plasma samples of 24 patients with $\mathrm{AD}$ and 29 healthy elderly normal control subjects were collected from either Seoul National University Bundang Hospital or Chung-Ang University Hospital (Table 1). Written informed consent was obtained from all patients who participated in this study or from their caregivers. $\mathrm{AD}$ cases were each diagnosed with a probable $\mathrm{AD}$ amnestic type on the basis of clinical criteria of the National Institute on Aging-Alzheimer's Association workgroups within a clinical setting with clinical data and follow-up longer than 6 month before inclusion into PiB-PET or CSF studies. Hence, the recruited patients were clinically wellcharacterized patients with $\mathrm{AD}$, and only they were included in the study. They were diagnosed with $A D$ after initial workup and had not shown any possibility of other neurodegenerative disorders except AD or secondary dementia disorders on the basis of more than 6 months of follow-up. The Mini Mental State Examination, identification of the ApoE phenotype, PET imaging with $\mathrm{PiB}$ and ${ }^{18} \mathrm{~F}$-fluorodeoxyglucose, and CSF analysis were performed. The characteristics of all participants are described in Table 1. Fiftyone additional plasma samples from elderly normal control subjects were included to avoid false positivity (Table 2).

\section{Sample preparation}

Blood samples were collected in heparin-containing tubes and centrifuged at $850 \times g$ for 30 minutes. The plasma (supernatant) was divided into aliquots and stored at $-80{ }^{\circ} \mathrm{C}$ until analysis. Plasma samples of patients with $\mathrm{AD}(n=11)$ and elderly normal control subjects $(n=9)$ were separately 
Table 1 Characterization of patients with Alzheimer's disease and healthy normal control subjects

\begin{tabular}{|c|c|c|}
\hline & $A D$ & $\begin{array}{l}\text { Healthy normal } \\
\text { control subjects }\end{array}$ \\
\hline Total sample number & 24 & 29 \\
\hline \multicolumn{3}{|l|}{ Sex } \\
\hline Female & $13(54.2 \%)$ & $16(55.2 \%)$ \\
\hline Male & $11(45.8 \%)$ & $13(44.8 \%)$ \\
\hline Age, years (SD) & $67.6( \pm 7.4)$ & $62.4( \pm 5.7)$ \\
\hline Education, years (SD) & $13.1( \pm 3.9)$ & $13.2( \pm 3.5)$ \\
\hline CDR-SOB, mean & 6.35 & 0.03 \\
\hline MMSE score, mean & 17.7 & 29.03 \\
\hline ApoE ع4, \% & 47.8 & 21.7 \\
\hline Note test & 1 & 0 \\
\hline Number of plasma samples & 24 & 29 \\
\hline CSF markers & 23 & 28 \\
\hline $\mathrm{A} \beta_{42}, \mathrm{pg} / \mathrm{ml}$, mean (SD) & $258.6( \pm 70.8)$ & $464.8( \pm 114.4)$ \\
\hline p-Tau, pg/ml, mean (SD) & $58.6( \pm 18.6)$ & $28.0( \pm 14.3)$ \\
\hline $\mathrm{t}$-Tau, pg/ml, mean (SD) & $132.1( \pm 61.8)$ & $62.1( \pm 20.3)$ \\
\hline PiB-PET number & 23 & 28 \\
\hline Mean SUVR & 1.57 & 1.14 \\
\hline FDG-PET number & 18 & 28 \\
\hline Mean SUVR & 0.9 & 1.06 \\
\hline
\end{tabular}

Abbreviations: $A \beta_{42}$ Amyloid- $\beta$ 1-42 peptide, $A D$ Alzheimer's disease, $A p o E$ Apolipoprotein E, CDR-SOB Clinical Dementia Rating Sum of Boxes, CSF Cerebrospinal fluid, $F D G^{18} \mathrm{~F}$-fluorodeoxyglucose, MMSE Mini Mental State Examination, PET Positron emission tomography, PiB ${ }^{11} \mathrm{C}$-Pittsburgh compound $\mathrm{B}, p$-Tau Phosphorylated tau protein, SUVR Standardized uptake value ratio, $t$-Tau Total tau protein

pooled for initial method optimization, whereas the remaining samples were assessed individually.

\section{Preparation of synthetic $A \beta_{42}$}

Lyophilized AggreSure $\beta$-Amyloid (1-42) peptide (AnaSpec, Fremont, CA, USA) and double-mutant F19S/ L34P $A \beta_{42}$ (mutA $\beta_{42}$; AnyGen Co., Ltd., Gwangju, South

Table 2 Supplementary information on healthy normal control subjects

\begin{tabular}{ll}
\hline & Healthy normal control subjects \\
\hline Total sample number & 51 \\
Sex & \\
$\quad$ Female & $21(43.1 \%)$ \\
$\quad$ Male & $29(56.9 \%)$ \\
Age, years (SD) & $62.25( \pm 7.89)$ \\
Education, years (SD) & $10.35( \pm 3.29)$ \\
CDR-SOB & 0.03 \\
MMSE score & 28.27 \\
\hline
\end{tabular}

CDR-SOB Clinical Dementia Rating Sum of Boxes, MMSE Mini Mental State Examination
Korea) were each dissolved in $50 \mathrm{mM}$ Tris/150 mM NaCl (pH 7.2) at a concentration of $1 \mathrm{mg} / \mathrm{ml}$ and then sonicated for 5 minutes to obtain a homogeneous solution. The peptide solution was further diluted with phosphate-buffered saline containing Tween 20 (PBST; Sigma-Aldrich, St. Louis, MO, USA) to a desired concentration of $10 \mu \mathrm{g} / \mathrm{ml}$. Solutions of diluted peptides were divided into aliquots and kept at $-80^{\circ} \mathrm{C}$ until further use.

\section{Thioflavin T assay}

$\mathrm{A} \beta$ aggregation was monitored using a thioflavin $\mathrm{T}$ (ThT) assay kit following the suggested protocol of the manufacturer (AnaSpec). Ninety microliters of test sample and 10 $\mu \mathrm{l}$ of $2 \mathrm{mM}$ ThT solution were added to each well of a 96well plate (Thermo Fisher Scientific, Waltham, MA, USA), and the plates were incubated for different lengths of time. Then, changes in ThT fluorescence intensity were detected by measuring excitation and emission wavelengths of 440 $\mathrm{nm}$ and $484 \mathrm{~nm}$, respectively, using a multispectrophotometer (Victor $3^{\mathrm{TM}}$; PerkinElmer, Waltham, MA, USA) with 15 seconds of shaking before reading and analysis.

\section{TEM}

$\mathrm{A} \beta \mathrm{O}$, protofibrils, and fibrils were characterized by TEM at various incubation times $(0,1,3,6,24$, and $48 \mathrm{~h})$. Five microliters of each sample was applied to carbon-coated TEM grids that had previously been glow-discharged for 3 minutes in the air and immediately negatively stained $(\sim 5$ seconds) with $2 \%$ uranyl acetate. Excess solution was removed with blotting paper. Image acquisition was carried out using a Philips CM10 transmission electron microscope (Philips Research, Eindhoven, The Netherlands) with an accelerating voltage of $80 \mathrm{kV}$.

\section{Sodium dodecyl sulfate-PAGE and immunoblotting}

The aggregation state of $A \beta$ was also analyzed by sodium dodecyl sulfate-PAGE followed by Western blotting. Synthetic peptide samples were electrophoresed on a 10$20 \%$ Tris-Tricine precast gel (Bio-Rad Laboratories, Hercules, CA, USA) and visualized by Coomassie blue staining (Bio-Rad Laboratories). After electrophoresis, the proteins were transferred to a polyvinylidene fluoride membrane (Bio-Rad Laboratories), which was blocked with 2\% Block Ace (Bio-Rad Laboratories) in Trisbuffered saline containing Tween 20 (TBST; SigmaAldrich) for $1 \mathrm{~h}$ at room temperature (RT) under conditions to reduce nonspecific binding. The membrane was incubated for $1 \mathrm{~h}$ at RT with a horseradish peroxidase (HRP)-conjugated FF51 antibody (FF51-HRP antibody; PeopleBio Inc., Seoul, South Korea) diluted in 0.4\% Block Ace in TBST. Proteins bound to the antibody were visualized with 3,3',5,5' -tetramethylbenzadine reagent (Sigma-Aldrich). 


\section{MDS for Alzheimer's disease}

A modified MDS was used to measure A $\beta O$ s. With this method, epitope-overlapping antibodies specific for the $\mathrm{N}$ terminus of $A \beta$ were used to capture and detect the $A \beta$ antigen in its multimeric or oligomeric form. Because MDS was initially developed to detect prion oligomers using prion antibodies, over 100 sets of antibodies against $A \beta$ were screened (data not shown). In addition, in-house A $\beta$ antibodies were developed. The mouse monoclonal antibody 6E10 (BioLegend, San Diego, CA, USA) and an in-house FF51-HRP antibody were chosen to detect A $\beta O$ s in our modified MDS, owing to their sensitivity and specificity. The epitopes for these antibodies overlap at the $\mathrm{N}$ terminus of A $\beta$. The FF51 antibody specifically recognizes amino acid residues $1-4$ of $A \beta$.

To use MDS, the 6E10 antibody was coated overnight at $4{ }^{\circ} \mathrm{C}$ in the wells of a 96 -well black plate (Thermo Fisher Scientific) at a dilution of $3 \mu \mathrm{g} / \mathrm{ml}$ in carbonatebicarbonate buffer (Sigma-Aldrich). The plates were blocked for $2 \mathrm{~h}$ with $0.4 \%$ Block Ace $(100 \mu \mathrm{l})$ at RT. After washing three times with PBS (Sigma-Aldrich), the plate was stored at $4{ }^{\circ} \mathrm{C}$ until use. Prior to the assay, aliquots of plasma samples were thawed at $37{ }^{\circ} \mathrm{C}$ for 15 minutes. Ten microliters of plasma, $4.04 \mu \mathrm{l}$ of HBR-1, a HAMA blocker (Scantibodies Laboratory, Santee, CA, USA), and PBST were mixed. We spiked the synthetic $\mathrm{A} \beta_{42}$ into plasma mixture and incubated it at $37{ }^{\circ} \mathrm{C}$ for the indicated durations.

The plasma sample mixture and serially diluted standards were added to each well of the plate in a total volume of $100 \mu \mathrm{l}$. The plates were incubated at RT for $1 \mathrm{~h}$. After washing three times with TBST, the FF51-HRP antibody in TBST containing $0.4 \%$ Block Ace was added to the wells, and the plate was incubated for $1 \mathrm{~h}$ at RT. To increase the sensitivity of detection, $100 \mu \mathrm{l} /$ well of enhanced chemiluminescence substrate solution (Rockland Immunochemicals Inc., Limerick, PA, USA) was used, and the luminescent signal was detected and quantified using a Victor $3^{\mathrm{TM}}$ multispectrophotometer.

\section{Measurement of $A \beta$ monomers $\left(A \beta_{40}\right.$ and $\left.A \beta_{42}\right)$}

Sandwich ELISAs were performed to measure $A \beta_{40}$ and $A \beta_{42}$ monomer levels. $A \beta_{40}$ monomers were captured with the 11A50 antibody (specific for the C-terminus of $\left.\mathrm{A} \beta_{40}\right)$ and detected with the $1 \mathrm{E} 11$ antibody conjugated to biotin. $A \beta_{42}$ monomers were captured with the $12 \mathrm{~F} 4$ antibody (specific for the C-terminus of $A \beta_{42}$ ) and detected with the 1E11 antibody conjugated to biotin.

\section{Statistics}

Statistical evaluations were performed using the MannWhitney $U$ test followed by the calculation of two-tailed $p$ values to determine the significance between groups.

\section{Results}

Measuring dynamic changes of $A \beta O$ levels with MDS

$\mathrm{A} \beta_{42}$ was characterized by gel electrophoresis, Western blotting, and TEM before it was spiked into plasma samples (Fig. 1). On the basis of Coomassie blue staining of dissolved $A \beta_{42}$, a smear band containing monomers and low-molecular-weight oligomers ranging between 4 and 18 $\mathrm{kDa}$ in size was detected, as shown in Fig. 1a. A doublemutant, $\mathrm{A} \beta_{42}$ (F19S/L34P; mutA $\left.\beta_{42}\right)$, was used as a monomeric $A \beta$ control because this mutant has significantly reduced aggregation potential as shown by Western blotting, which yielded a specific band with an approximate molecular weight of 4-5 kDa. The specificities of the wild-type and mutant monomer bands were verified by MDS, as shown in Fig. 1b. MDS was capable of detecting $A \beta O$ s composed of $A \beta_{42}$ in a concentration-dependent manner employing half serial dilutions from $100 \mathrm{ng}$ to $3.13 \mathrm{ng}$, whereas no signal was detected when using mutA $\beta_{42}$. Thus, MDS specifically recognizes $A \beta O$ s but not $A \beta$ monomers.

As shown in Fig. 1c, changes in $A \beta_{42}$ oligomer levels over an incubation period of $144 \mathrm{~h}$ were monitored using an MDS and the ThT assay. The MDS detected a continual increase in $A \beta_{42}$ oligomer levels from 0 to $24 \mathrm{~h}$ after the start of incubation, followed by a decline until $120 \mathrm{~h}$, at which point the levels remained relatively stable. Conversely, the ThT assay showed an increase in $A \beta_{42}$ oligomer levels from 0 to $48 \mathrm{~h}$, at which point changes in $\beta$-sheet formation were observed. TEM (Fig. 1d) revealed a wide range (1-5 nm) of $\mathrm{A} \beta \mathrm{O}$ diameters, with few protofibrils observed. These findings support the MDS results obtained at the start of incubation $(0 \mathrm{~h})$ in terms of the formation of $A \beta O s$. Within $1 \mathrm{~h}$ after the start of incubation, the $\mathrm{A} \beta_{42}$ monomers readily formed large, spherical $A \beta O$ s ranging from 10 to $15 \mathrm{~nm}$ in size, and numerous protofibrils were observed (lengths of $50-80 \mathrm{~nm}$ ). A TEM image at $3 \mathrm{~h}$ revealed the elongation of A $\mathrm{BOs}$ to form protofibrils, and significant amounts of large A $\mathrm{OOs}$ and protofibrils were observed at $6 \mathrm{~h}$ by TEM. A substantial decline in the MDS signal was observed during the time interval of $24-48 \mathrm{~h}$ after the start of incubation. TEM revealed the predominance of protofibrils and fibrils (over $120 \mathrm{~nm}$ in length) at $24 \mathrm{~h}$, whereas A $\beta O$ s were rarely observed, and the continuous maturation of protofibrils resulted in an increase in $A \beta_{42}$ fibrils at $48 \mathrm{~h}$. On the basis of these findings, the MDS sensitively and specifically detects oligomeric and protofibril forms of $A \beta$, permitting their quantification, whereas the ThT assay is not sensitive and was incapable of detecting increases in $A \beta$ fibril levels, including diverse types of amyloid fibrils [34].

Plasma is cleared of $A \beta$ through several intricate mechanisms of aggregation or sequestration [35-38]. Therefore, pooled samples of plasma from patients with $\mathrm{AD}$ or from normal control subjects were spiked with different concentrations of $A \beta_{42}$ to compare differences in $A \beta_{42}$ recovery (Fig. 2a and b). A $\beta O$ levels were reduced in accordance 


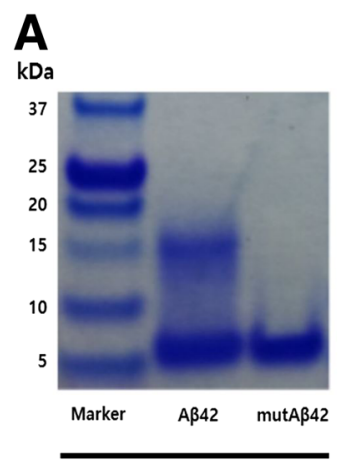

$4-12 \%$ Aspartate Gel
$\mathrm{kDa}$

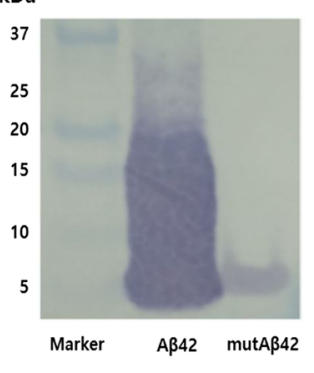

Western blot

B

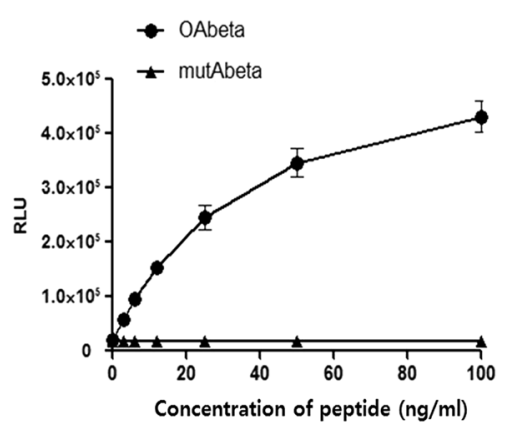

$\rightarrow$ ThT

C

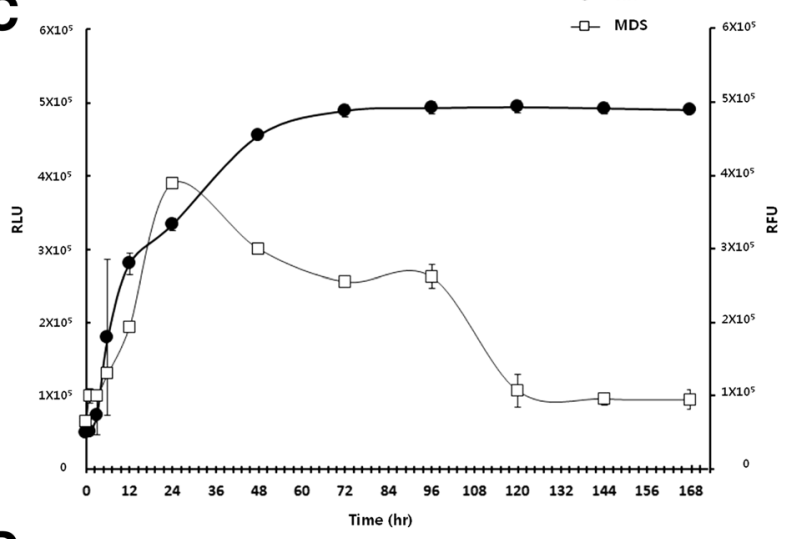

D
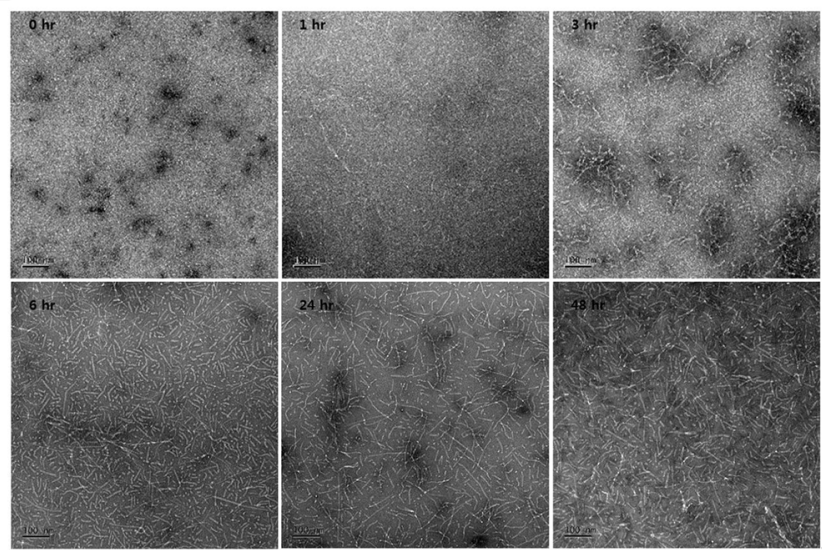

Fig. 1 Detection of synthetic amyloid- $\beta$ 1-42 peptide $\left(A \beta_{42}\right)$. a Freshly dissolved synthetic $A \beta_{42}$ and double-mutant $A \beta_{42}$ (mutA $\left.\beta_{42}\right)$ were visualized on the $4-12 \%$ aspartate PAGE gel by Coomassie blue staining and on the Western blot by FF51-horseradish peroxidase (HRP) antibody. $\mathbf{b}$ Standard curve for multimer detection system (MDS). Synthetic peptides were serially diluted and measured by 6E10/FF51-HRP MDS assay. Change of A $\beta_{42}$ over different times ( $\mathbf{c}$ and $\mathbf{d}$ ). $A \beta_{42}$ was incubated at $37^{\circ} \mathrm{C}$ at the indicated time points. To measure amyloid- $\beta$ oligomer (ABO), an MDS assay was used (c), and fibrillization of $A \beta_{42}$ over time was measured by thioflavin $T$ (ThT) binding assay (d). TEM images over time by $A \beta_{42}$ in buffer vehicle are shown. Data are mean $\pm S D$. RLU Relative luminescence units, RFU Relative fluorescence units

with the $A \beta_{42}$ concentrations used for spiking when compared with $A \beta O$ levels in a solution spiked with buffer. Lower concentrations of spiked $A \beta_{42}$ yielded smaller differences in the formation of $A \beta O$ s in the pooled plasma of patients with $\mathrm{AD}$ compared with that of control subjects. For subsequent experiments, $10 \mathrm{ng} / \mathrm{ml} \mathrm{A} \beta_{42}$ was chosen for spiking into plasma because this concentration yielded the smallest measurable difference in the recovery rate of $A \beta$ when comparing plasma from patients with $\mathrm{AD}$ with that of normal control subjects. Eleven plasma samples from patients with $\mathrm{AD}$ and nine from elderly normal control subjects were separately pooled for each group. Pooled 

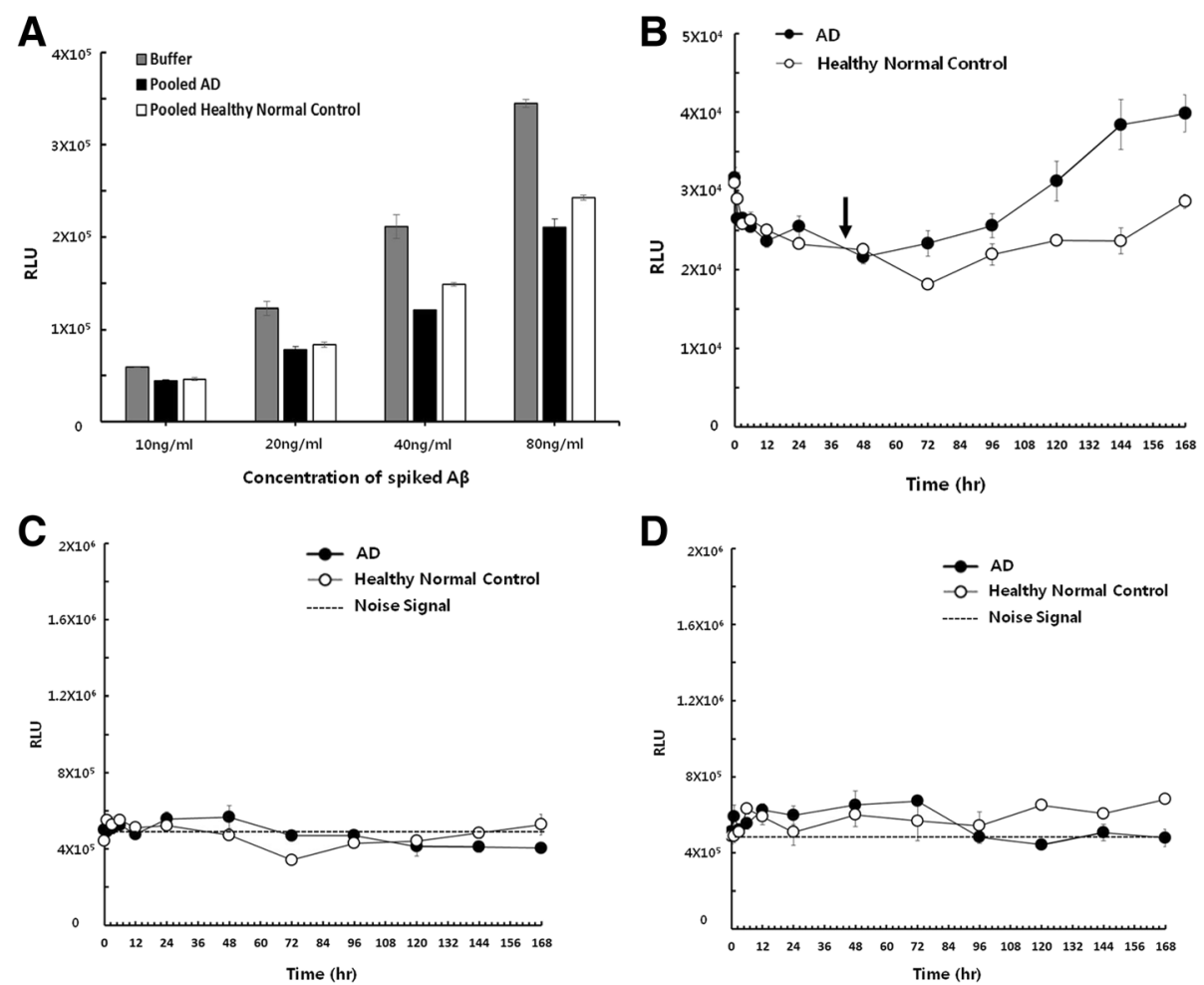

Fig. 2 Changes of amyloid- $\beta$ oligomers (ABOs) and amyloid- $\beta$ (AB) monomers in pooled plasma of patients with Alzheimer's disease (AD) and healthy normal control subjects. a After being spiked with different concentrations of $A \beta_{42}$ in buffer vehicle, pooled $A D$ plasma, and pooled healthy normal control plasma, oligomers were measured using a multimer detection system (MDS) at 0 h. b Pooled plasma samples were incubated at $37{ }^{\circ} \mathrm{C}$ after being spiked with $10 \mathrm{ng} / \mathrm{ml} \mathrm{A} \beta_{42}$. Changes of $A \beta_{42}$ levels at various time points were measured by MDS. Levels of $A \beta_{40}$ (c) and $A \beta_{42}$ (d) after being spiked with $10 \mathrm{ng} / \mathrm{ml} A \beta_{42}$ in pooled human plasma. Pooled plasma samples were incubated at $37^{\circ} \mathrm{C}$ after $10 \mathrm{ng} / \mathrm{ml} \mathrm{A} \beta_{42}$ were spiked. Data are mean \pm SD. RLU Relative luminescence units. Arrow indicated no change in oligomer levels after an incubation period of $24 \mathrm{~h}$

samples were incubated at $37^{\circ} \mathrm{C}$ after spiking with $\mathrm{A} \beta_{42}(10$ $\mathrm{ng} / \mathrm{ml})$, and the presence of oligomers was measured using MDS at various time points after the start of incubation. As shown in Fig. 2b, both groups exhibited a gradual decline in oligomer levels over $48 \mathrm{~h}$ of incubation; the two groups demonstrated similar levels over this time period. After 48 $\mathrm{h}$ of incubation, distinct dynamic changes were observed between the plasma from patients with $\mathrm{AD}$ and that of elderly normal control subjects. Larger increases in A $\beta O$ levels were observed in the plasma from patients with $\mathrm{AD}$ after $48 \mathrm{~h}$ of incubation, and levels continually increased throughout the rest of the incubation period. In contrast, $\mathrm{A} \beta \mathrm{O}$ levels in the plasma from elderly normal control subjects gradually decreased until $72 \mathrm{~h}$ after the start of incubation, then rebounded with a considerable increase until 144 $h$. The largest differences in $A \beta O$ levels between plasma from patients with $\mathrm{AD}$ and plasma from elderly normal control subjects were observed after $144 \mathrm{~h}$ of incubation following spiking with $A \beta$. Changes in $A \beta_{40}$ and $A \beta_{42}$ levels after spiking with $A \beta_{42}$ were also measured by performing 11A50/1E11-biotin ELISA and 12F4/1E11-biotin ELISA. $A \beta_{40}$ and $A \beta_{42}$ levels remained relatively unchanged over the incubation period (Fig. 2c and d), whereas significant increases in the oligomer forms, as measured by MDS, were observed in the plasma from patients with $\mathrm{AD}$ after $48 \mathrm{~h}$ of incubation but not in plasma from elderly normal control subjects. Additional experiments were then performed to confirm whether the differential changes in the $\mathrm{A} \beta$ forms were discernible in individual plasma samples.

Plasma samples corresponding to individuals included in the pooled groups (patients with $\mathrm{AD}$ and elderly normal control subjects) were spiked with $A \beta_{42}$. Then, MDS was used to monitor changes in $\mathrm{A} \beta \mathrm{O}$ levels during incubation from 0 to $144 \mathrm{~h}$ (Fig. 3a and b). Each sample was also tested in the absence of synthetic $A \beta$ for comparison. As shown in Fig. 3b1, $\mathrm{A} \beta \mathrm{O}$ levels in plasma samples from patients with $\mathrm{AD}$ and elderly normal control subjects overlapped without a significant difference $(p=0.6761)$ at $0 \mathrm{~h}$, regardless of spiking. In contrast, after $144 \mathrm{~h}$ of incubation, distinct oligomer levels were detected in $A \beta_{42}$-spiked samples from the $\mathrm{AD}$ and control groups $(p<0.01)$ on the basis of MDS measurements (Fig. 3b2). Plasma samples from the $\mathrm{AD}$ group also demonstrated higher $\mathrm{A} \beta \mathrm{O}$ levels than normal control plasma, although this difference was significant 

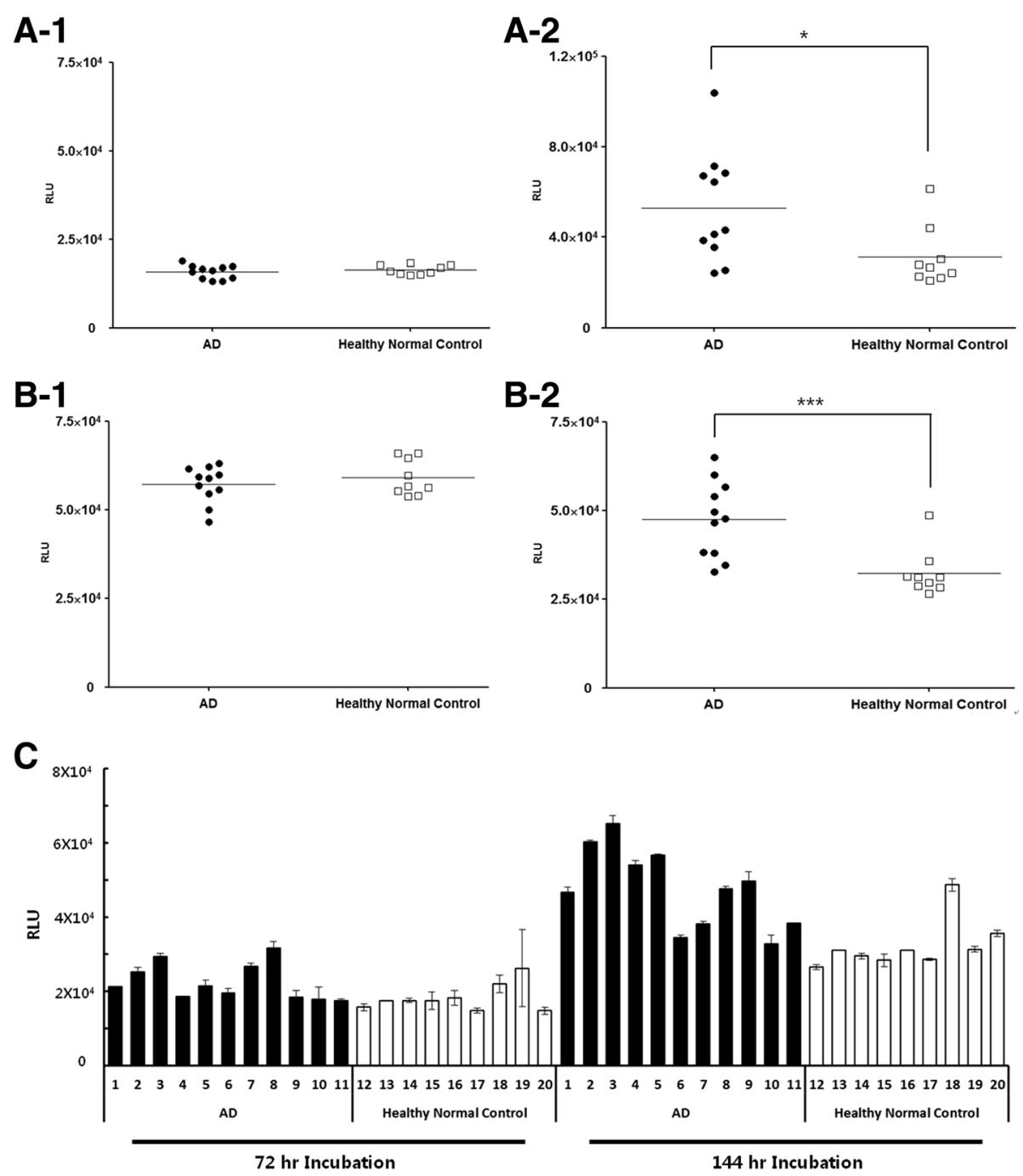

$72 \mathrm{hr}$ Incubation

144 hr Incubation

Fig. 3 Effect of amyloid- $\beta$ 1-42 peptide $\left(A \beta_{42}\right.$ ) spiking and incubation in individual subjects (Alzheimer's disease $[A D]$ and healthy normal control subjects). Each sample was incubated under the indicated conditions. To measure amyloid- $\beta$ oligomers, a multimer detection system (MDS) assay was used. (a1) $0 \mathrm{ng} / \mathrm{ml} \mathrm{A} \beta_{42}$ at $0 \mathrm{~h},(\mathbf{a} 2) 0 \mathrm{ng} / \mathrm{ml} \mathrm{A} \beta_{42}$ at $144 \mathrm{~h}$, (b1) $10 \mathrm{ng} / \mathrm{ml} \mathrm{A} \beta_{42}$ at $0 \mathrm{~h}$, and (b2) $10 \mathrm{ng} / \mathrm{ml} \mathrm{A} \beta_{42}$ at $144 \mathrm{~h}$. (c) Dynamic changes of $A \beta_{42}$ incubation in individual subjects at $72 \mathrm{~h}$ and $144 \mathrm{~h}$. Each sample was incubated for $72 \mathrm{~h}$ and $144 \mathrm{~h}$ after being spiked with $10 \mathrm{ng} / \mathrm{ml}$ $A \beta_{42}$ and measured by MDS. ${ }^{*} p<0.05 ;{ }^{* *} p<0.01$. RLU Relative luminescence units

but the $p$ value was $<0.05$ (Fig. 3a2). Similar to the results of the pooled plasma experiment, $A \beta$ dynamics were evident from 48 to $144 \mathrm{~h}$ in individual samples from both groups. As shown in Fig. 3c, substantial increases in oligomer levels were confirmed in the majority of plasma samples from patients with $\mathrm{AD}$, whereas samples from normal control subjects demonstrated no significant increase. No increases in oligomer levels were observed with synthetic $A \beta_{42}$ in buffer solution after an incubation time of $24 \mathrm{~h}$.

\section{Differential dynamic changes in $A \beta$ levels in plasma of patients with $A D$ versus that of elderly normal control subjects}

To evaluate and verify our findings on a larger scale, 24 plasma samples from clinically well-characterized cases of $\mathrm{AD}$ and 80 from elderly normal control subjects were examined after spiking with synthetic $A \beta(10 \mathrm{ng} / \mathrm{ml})$ and incubating for $144 \mathrm{~h}$. The dynamic changes of oligomer formation were measured using MDS, and oligomer levels were different between the $\mathrm{AD}$ and control groups with a sensitivity of $83.33 \%$, a specificity of $90.00 \%$, an AUC of 0.8969 , and a $p$ value $<0.0001$ (Fig. 4).

\section{Discussion}

MDS was initially developed to detect prion disease. This method consists of a sandwich ELISA that exclusively detects oligomeric forms of antigens and relies on two different epitope-overlapping antibodies to capture and detect antigens by creating steric hindrance over a specific epitope $[33,39]$. MDS was modified to detect $A \beta O$ s for $A D$ 


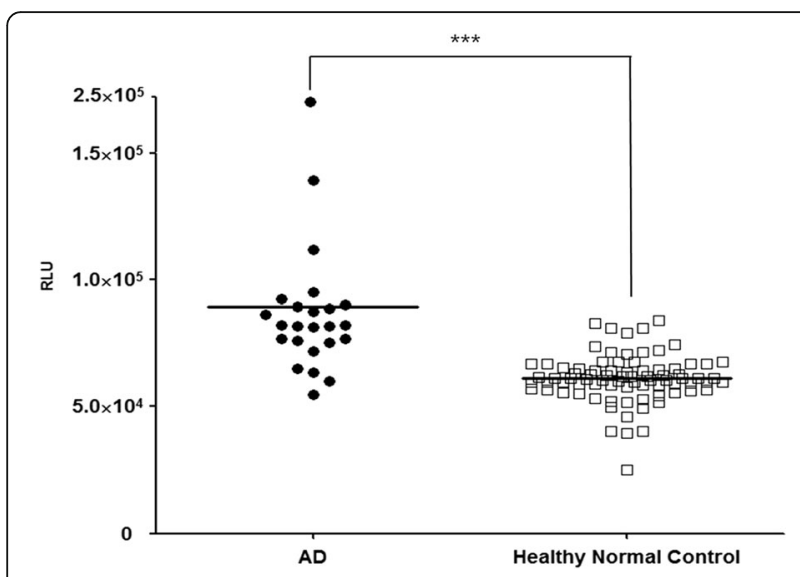

Fig. 4 Effect of amyloid- $\beta$ 1-42 peptide $\left(A \beta_{42}\right)$ spiking and incubation in large scale (Alzheimer's disease [AD] and healthy normal control subjects). Each sample was incubated for $144 \mathrm{~h}$ after being spiked with $10 \mathrm{ng} / \mathrm{ml} \mathrm{A} \beta_{42}$. To measure amyloid- $\beta$ oligomers, a multimer detection system assay was used. ${ }^{* *} p<0.001$ versus healthy normal control values. RLU Relative luminescence units

diagnosis using two epitope-overlapping $A \beta$ antibodies specific for the $\mathrm{N}$-terminus amino acids $1-18$ of $A \beta_{42}$.

We monitored the formation of $\mathrm{A} \beta \mathrm{O}$, protofibrils, and fibrils from synthetic $A \beta_{42}$ in PBST buffer employing two methods: a ThT assay and MDS (Fig. 1). A $\beta$ oligomerization was closely correlated between these two assays. When the time-course changes of synthetic A $\beta$ in PBST buffer were monitored by MDS, ThT assay, and TEM, the MDS detected a continuous increase of $A \beta_{42}$ oligomer levels from 0 to $24 \mathrm{~h}$ from the start of incubation, followed by a decline until 120 h. Conversely, an increase of fluorescent signal in the ThT assay was correlated with an increase of $A \beta_{42}$ fibril formation, which was confirmed by TEM imaging (Fig. 1c and d). The MDS signal decreased at that time of fibrillization; thus, it would be reasonable to assume that MDS detected specifically oligomeric and protofibril forms of $A \beta$. During the early phase of incubation, MDS revealed decreasing $\mathrm{A} \beta \mathrm{O}$ levels accompanied by the formation of protofibrils and fibrils, but the levels detected by the ThT assay were stable. Thus, MDS is able to detect $A \beta O$ s during the early stage of $A \beta$ oligomerization. Decreasing $A \beta O$ levels, as measured by MDS, in conjunction with the formation of protofibrils and fibrils is potentially explained by two hypotheses. First, MDS has a higher sensitivity for oligomers than for protofibrils or fibrils. Second, the total number of oligomers decreases over time. After full oligomerization, the spiked $A \beta$ converts to protofibrils, resulting in decreased MDS signals.

When synthetic $A \beta_{42}$ is spiked into plasma, the plasma composition may dictate and interfere with $A \beta$ oligomerization. Difficulties in detecting spiked synthetic $A \beta_{42}$ via routine ELISA may be attributable to the presence of many different interfering factors in the plasma, which bind to the spiked synthetic $A \beta_{42}$ and thus reduce its detection. These factors include naturally occurring $\mathrm{A} \beta$ autoantibodies, albumin, fibrinogen, immunoglobulin, ApoJ, ApoE, transthyretin, $\alpha_{2}$-macroglobulin, serum amyloid P component, plasminogen, and amylin [35-38, 40]. In addition, these molecules in bodily fluids could also inhibit $A \beta$ fibrillization. Our hypothesis was that the composition of those components in blood from patients with $\mathrm{AD}$ would be different from that in healthy control subjects. If the same amount of $A \beta$ were spiked into $A D$ and control plasma samples, a different phenomenon would be observed between the two groups.

In this study, when equal amounts of synthetic $A \beta_{42}$ were spiked into plasma, MDS signals for $\mathrm{A} \beta \mathrm{O}$ s declined from 0 to $48 \mathrm{~h}$ in both groups (Fig. $2 \mathrm{~b}$ ), potentially due to $\mathrm{A} \beta \mathrm{O}$ binding to interfering factors. Although binding affinities and $A \beta$ epitopes likely vary among different binding factors, high concentrations in the plasma would likely result in the scavenging of spiked synthetic $A \beta_{42}$. Binding of these factors to $A \beta$ may naturally influence the normal functions and sequestration of $A \beta$, leading to clearance and reduced oligomerization potential in elderly normal persons [35, 37].

Forty-eight hours after spiking with $A \beta_{42}, A \beta O$ levels measured by MDS began to increase in the plasma from patients with $\mathrm{AD}$ but not in that of normal control subjects (Fig. 2b). Patients with AD may exhibit different binding profiles based on their plasma composition in the context of spiked synthetic $A \beta_{42}$, which in turn may increase oligomerization potential and decrease sequestration capacity. Alternatively, the characteristics of endogenous plasma $A \beta$ may differ between the two groups, permitting the dynamic changes of $A \beta$ oligomerization to be detected.

It is challenging work to detect crude $A \beta O$ s in plasma because the concentrations of $A \beta$ in blood are very low. Furthermore, the concentrations of $\mathrm{A} \beta \mathrm{O}$ s would be a subset of total $\mathrm{A} \beta$ in blood. The size of $4.5 \mathrm{kDa}$ could be another reason why the MDS failed to measure the endogenous plasma $A \beta$ from patients with $A D$. As shown in Fig. 3, the MDS did not discriminate between patients with $\mathrm{AD}$ and healthy normal control subjects without incubation conditions. Even though incubation of plasma samples without spiking external $A \beta$ made slight differences between AD and normal control samples, the difference was not significant.

However, even at ultralow concentrations, the formation of $\mathrm{A} \beta \mathrm{O}$ in the blood of patients with $\mathrm{AD}$ may be initiated via incubation with spiked synthetic $A \beta_{42}$. The first $48 \mathrm{~h}$ of incubation represent a slow nucleation-dependent oligomerization phase during which ultralow concentrations of $A \beta O$ nuclei are required to bind to spiked synthetic $A \beta_{42}$. The period after $48 \mathrm{~h}$ and up to $144 \mathrm{~h}$ represents a rapid-growth phase for the formation of oligomers, protofibrils and fibrils, surpassing the critical detection limit [34, 41-43]. As previously mentioned, the 
interfering factors may be saturated with spiked $A \beta$; hence, they may not affect to MDS signal even after $48 \mathrm{~h}$ of incubation. In addition, the binding interactions between $A \beta$ and another $A \beta$ may be stronger than other interfering factors for oligomerization. In previous studies, by using protein misfolding cyclic amplification technology, researchers were able to differentiate $A \beta O$ levels by catalyzing the misfolding and amplification of $A \beta$ aggregates by spiking $A \beta_{42}$ into the CSF of patients with $A D$ and control individuals [44]. However, spiking $A \beta$ into the plasma to differentiate $A \beta O$ has not previously been published.

We observed the phenomenon that MDS signals of control subjects were still stable while we spiked the same large amount of synthetic peptide into both $\mathrm{AD}$ and normal plasma samples, even after the identical incubation step. Currently, we do not know the exact cause of the phenomenon. Oligomerization of $A \beta$ could be influenced by potential factors in plasma of patients with $\mathrm{AD}$ but not plasma samples from normal control. The concentrations of these potential factors could be different in the disease state, but they may not be present in the normal state.

We detected differential $\mathrm{A} \beta \mathrm{O}$ dynamic changes in the blood of patients with $\mathrm{AD}$ and normal control subjects, but a direct correlation between blood and brain pathology remains uncharacterized. The properties of $A \beta$ plaques in the brain may differ from those in the blood because $A \beta$ in the blood also originates from amyloid precursor protein metabolism in skeletal muscle, organs, skin, and peripheral cells $[45,46]$. However, on the basis of previous reports, $A \beta$ peptides cross the blood-brain barrier, resulting in elevated $A \beta$ levels in the CSF and plasma during intracerebroventricular injection of synthetic $A \beta_{42}$ monomers into normal imprinting control region mice $[47,48]$. It will be interesting to identify the correlation between $\mathrm{A} \beta \mathrm{O}$ concentrations in the plasma and amyloid plaque deposition in the brains of patients with $\mathrm{AD}$.

\section{Conclusions}

Spiked synthetic $A \beta_{42}$ induced differential dynamic changes in $\mathrm{A} \beta \mathrm{O}$ levels in the plasma of patients with $\mathrm{AD}$ compared with that of normal control subjects, as detected by MDS. These observations appear to support our hypothesis that the plasma composition and/or characteristics of endogenous $A \beta$ in patients with $A D$ versus normal healthy persons are different. To our knowledge, there have been no published reports involving the spiking of $A \beta$ into plasma. The characterization of differential $A \beta$ oligomerization dynamic changes may contribute to the development of blood-based biomarkers for AD. However, further studies are required to elucidate the mechanisms underlying the formation of $\mathrm{A} \beta \mathrm{O}$. Longitudinal studies undertaken during the predementia stage of $\mathrm{AD}$ should also be carried to assess clinical applications for the early detection and monitoring of this disease.

\section{Abbreviations}

$A \beta$ : Amyloid- $\beta ; A \beta_{42}$ : Amyloid- $\beta$ 1-42 peptide; $A \beta O$ : Amyloid- $\beta$ oligomer; AD: Alzheimer's disease; Apo: Apolipoprotein; CDR-SOB: Clinical Dementia Rating Sum of Boxes; CSF: Cerebrospinal fluid; ELISA: Enzyme-linked immunosorbent assay; FDG: ${ }^{18}$ F-fluorodeoxyglucose; HRP: Horseradish peroxidase; LL: Interleukin; MDS: Multimer detection system; miR: MicroRNA; MMSE: Mini Mental State Examination; PBST: Phosphate-buffered saline containing Tween 20; PET: Positron emission tomography; PiB: ${ }^{11} \mathrm{C}$-Pittsburgh compound B; p-Tau: Phosphorylated tau protein; RFU: Relative fluorescence unit; RLU: Relative luminescence unit; RT: Room temperature; SCD40: Soluble CD40; SCD40L: Soluble CD40 ligand; SUVR: Standardized uptake value ratio; TBST: Tris-buffered saline containing Tween 20; TEM: Transmission electron microscopy; ThT: Thioflavin T; t-Tau: Total tau protein

\section{Funding}

This work was supported by grants from the Korean Health Technology R\&D Project (HI14C3331) through the Korean Health Industry Development Institute (KHIDI), the Korean Ministry of Health \& Welfare, and the National Research Foundation of Korea (NRF-2017R1A2B4012636).

\section{Availability of data and materials}

The datasets used and/or analyzed during the present study are available from the corresponding author on reasonable request.

\section{Authors' contributions}

SSAA planned, organized and designed all experiments and results, including the writing of the manuscript. BL planned, organized and designed all experiments and results, including the writing of the manuscript. JSY planned and performed all experiments and results, including the writing of the manuscript. KL planned and performed all experiments and results. GJK planned and performed all experiments and results. RL planned and organized all experiments. SWK planned and organized all experiments. SK planned and organized all experiments. YHP planned and collected clinical samples. MJW planned and collected clinical samples. YSY planned and collected clinical samples. YCY planned and collected clinical samples. SYK planned and organized all experiments and results, collected clinical samples, and wrote the manuscript. All authors read and approved the final manuscript.

\section{Ethics approval and consent to participate}

The study was approved by institutional review board of Seoul National University Bundang Hospital and Chung-Ang University Hospital [B-0905-075-003, B-1202145-003, C2012048(743), C2013142(1102)]. Written informed consent was obtained from all patients who participated in this study or from their caregivers.

Consent for publication

All authors consented to publication of this paper.

\section{Competing interests}

The authors declare that they have no competing interests.

\section{Publisher's Note}

Springer Nature remains neutral with regard to jurisdictional claims in published maps and institutional affiliations.

\section{Author details}

${ }^{1}$ Department of Bionanotechnology, Gachon University, Incheon, Republic of Korea. ${ }^{2}$ Research and Development, PeopleBio Inc., Gyeonggi-do, Republic of Korea. ${ }^{3}$ Department of Neurology, Seoul National University College of Medicine \& Neurocognitive Behavior Center, Seoul National University Bundang Hospital, 300 Gumidong, Bundang-gu, Seongnam-si, Gyeonggi-do 463-707, Republic of Korea. ${ }^{4}$ Department of Neurology, Veterans Health Service Medical Center, Seoul, Republic of Korea. ${ }^{5}$ Department of Neurology, Chung-Ang University College of Medicine, Seoul, Republic of Korea. 
Received: 24 April 2017 Accepted: 12 September 2017

Published online: 17 October 2017

\section{References}

1. Hardy JA, Higgins GA. Alzheimer's disease: the amyloid cascade hypothesis. Science. 1992;256(5054):184-5.

2. $\quad$ Querfurth HW, LaFerla FM. Alzheimer's disease. N Engl J Med. 2010;362(4): 329-44

3. Hardy J, Selkoe DJ. The amyloid hypothesis of Alzheimer's disease: progress and problems on the road to therapeutics. Science. 2002;297(5580):353-6.

4. Jan A, Adolfsson O, Allaman I, Buccarello AL, Magistretti PJ, Pfeifer A, et al. $A \beta 42$ neurotoxicity is mediated by ongoing nucleated polymerization process rather than by discrete $A \beta 42$ species. J Biol Chem. 2011;286(10): 8585-96.

5. Haass C, Selkoe DJ. Soluble protein oligomers in neurodegeneration: lessons from the Alzheimer's amyloid $\beta$-peptide. Nat Rev Mol Cell Biol. 2007;8(2): $101-12$.

6. Kittelberger KA, Piazza F, Tesco G, Reijmers LG. Natural amyloid- $\beta$ oligomers acutely impair the formation of a contextual fear memory in mice. PLoS One. 2012:7(1), e29940.

7. Poling A, Morgan-Paisley K, Panos JJ, Kim EM, O'Hare E, Cleary JP, et al. Oligomers of the amyloid- $\beta$ protein disrupt working memory: confirmation with two behavioral procedures. Behav Brain Res. 2008;193(2):230-4.

8. Cleary JP, Walsh DM, Hofmeister JJ, Shankar GM, Kuskowski MA, Selkoe DJ, Ashe $\mathrm{KH}$. Natural oligomers of the amyloid- $\beta$ protein specifically disrupt cognitive function. Nat Neurosci. 2005;8(1):79-84

9. Ferreira ST, Vieira MN, De Felice FG. Soluble protein oligomers as emerging toxins in Alzheimer's and other amyloid diseases. IUBMB Life. 2007:59(4-5):332-45.

10. Benilova I, Karran E, De Strooper B. The toxic A oligomer and Alzheimer's disease: an emperor in need of clothes. Nat Neurosci. 2012;15(3):349-57.

11. Kummer MP, Heneka MT. Truncated and modified amyloid- $\beta$ species. Alzheimers Res Ther. 2014;6(3):28.

12. Choi YJ, Chae S, Kim JH, Barald KF, Park JY, Lee SH. Neurotoxic amyloid $\beta$ oligomeric assemblies recreated in microfluidic platform with interstitial level of slow flow. Sci Rep. 2013;3:1921.

13. Cedazo-Minguez A, Winblad B. Biomarkers for Alzheimer's disease and other forms of dementia: clinical needs, limitations and future aspects. Exp Gerontol. 2010;45(1):5-14

14. Blennow $K$, Hampel $H$, Weiner M, Zetterberg $H$. Cerebrospinal fluid and plasma biomarkers in Alzheimer disease. Nat Rev Neurol. 2010;6(3):131-44.

15. Yang L, Rieves D, Ganley C. Brain amyloid imaging-FDA approval of florbetapir F18 injection. N Engl J Med. 2012;367(10):885-7.

16. Ewers M, Sperling RA, Klunk WE, Weiner MW, Hampel H. Neuroimaging markers for the prediction and early diagnosis of Alzheimer's disease dementia. Trends Neurosci. 2011;34(8):430-42.

17. Nordberg A, Rinne JO, Kadir A, Langstrom B. The use of PET in Alzheimer disease. Nat Rev Neurol. 2010;6(2):78-87.

18. Wang C, Cui Y, Yang J, Zhang J, Yuan D, Wei Y, et al. Combining serum and urine biomarkers in the early diagnosis of mild cognitive impairment that evolves into Alzheimer's disease in patients with the apolipoprotein E4 genotype. Biomarkers. 2015;20(1):84-8.

19. Ma L, Chen J, Wang R, Han Y, Zhang J, Dong W, et al. The level of Alzheimer-associated neuronal thread protein in urine may be an important biomarker of mild cognitive impairment. J Clin Neurosci. 2015;22(4):649-52.

20. Ma L, Wang R, Han Y, Sheng S, Zhu J, Ji Z, et al. Development of a novel urine Alzheimer-associated neuronal thread protein ELISA kit and its potential use in the diagnosis of Alzheimer's disease. J Clin Lab Anal. 2015; 30(4):308-14.

21. Bermejo-Pareja F, Antequera D, Vargas T, Molina JA, Carro E. Saliva levels of Abeta1-42 as potential biomarker of Alzheimer's disease: a pilot study. BMC Neurol. 2010;10:108.

22. Mapstone M, Cheema AK, Fiandaca MS, Zhong X, Mhyre TR, MacArthur LH, et al. Plasma phospholipids identify antecedent memory impairment in older adults. Nat Med. 2014;20(4):415-8.

23. Ait-ghezala G, Abdullah L, Volmar CH, Paris D, Luis CA, Quadros A, et al. Diagnostic utility of APOE, soluble CD40, CD40L, and $A \beta_{1-40}$ levels in plasma in Alzheimer's disease. Cytokine. 2008:44(2):283-7.

24. Doecke JD, Laws SM, Faux NG, Wilson W, Burnham SC, Lam CP, et al. Bloodbased protein biomarkers for diagnosis of Alzheimer disease. Arch Neurol. 2012;69(10):1318-25
25. Ray S, Britschgi M, Herbert C, Takeda-Uchimura Y, Boxer A, Blennow K, et al. Classification and prediction of clinical Alzheimer's diagnosis based on plasma signaling proteins. Nat Med. 2007;13(11):1359-62.

26. Xia W, Yang T, Shankar G, Smith IM, Shen Y, Walsh DM, Selkoe DJ. A specific enzyme-linked immunosorbent assay for measuring $\beta$-amyloid protein oligomers in human plasma and brain tissue of patients with Alzheimer disease. Arch Neurol. 2009;66(2):190-9.

27. Bjorkqvist M, Ohlsson M, Minthon L, Hansson O. Evaluation of a previously suggested plasma biomarker panel to identify Alzheimer's disease. PLoS One. 2012;7(1), e29868

28. Yang T, Hong S, O'Malley T, Sperling RA, Walsh DM, Selkoe DJ. New ELISAs with high specificity for soluble oligomers of amyloid $\beta$-protein detect natural $A \beta$ oligomers in human brain but not CSF. Alzheimers Dement. 2013;9(2):99-112.

29. Hyman BT, Smith C, Buldyrev I, Whelan C, Brown H, Tang MX, Mayeux R. Autoantibodies to amyloid- $\beta$ and Alzheimer's disease. Ann Neurol. 2001; 49(6):808-10.

30. Irizarry MC. Biomarkers of Alzheimer disease in plasma. NeuroRx. 2004;1(2): 226-34.

31. Thambisetty M, Lovestone S. Blood-based biomarkers of Alzheimer's disease: challenging but feasible. Biomark Med. 2010;4(1):65-79.

32. Hampel $H$, Shen $Y$, Walsh DM, Aisen $P$, Shaw LM, Zetterberg $H$, et al. Biological markers of amyloid $\beta$-related mechanisms in Alzheimer's disease. Exp Neurol. 2010;223(2):334-46.

33. An SSA, Lim KT, Oh HJ, Lee BS, Zukic E, Ju YR, et al. Differentiating blood samples from scrapie infected and non-infected hamsters by detecting disease-associated prion proteins using multimer detection system. Biochem Biophys Res Commun. 2010;392(4):505-9.

34. Biancalana M, Koide S. Molecular mechanism of thioflavin-T binding to amyloid fibrils. Biochim Biophys Acta. 2010;1804(7):1405-12.

35. Wang YJ, Zhou HD, Zhou XF. Clearance of amyloid- $\beta$ in Alzheimer's disease: progress, problems and perspectives. Drug Discov Today. 2006;11(19-20):931-8

36. Sehlin D, Söllvander S, Paulie S, Brundin R, Ingelsson M, Lannfelt L, et al. Interference from heterophilic antibodies in amyloid- $\beta$ oligomer ELISAs. J Alzheimers Dis. 2010;21(4):1295-301.

37. Kuo YM, Emmerling MR, Lampert HC, Hempelman SR, Kokjohn TA, Woods $A S$, et al. High levels of circulating $A \beta 42$ are sequestered by plasma proteins in Alzheimer's disease. Biochem Biophys Res Commun. 1999;257(3):787-91.

38. Kuo YM, Kokjohn TA, Kalback W, Luehrs D, Galasko DR, Chevallier N, et al. Amyloid$\beta$ peptides interact with plasma proteins and erythrocytes: implications for their quantitation in plasma. Biochem Biophys Res Commun. 2000;268(3):750-6.

39. Lim K, Kim SY, Lee B, Segarra C, Kang S, Ju Y, et al. Magnetic microparticlebased multimer detection system for the detection of prion oligomers in sheep. Int J Nanomed. 2015;10(Spec Iss):241-50.

40. Ono K, Noguchi-Shinohara M, Samuraki M, Matsumoto Y, Yanase D, et al. Blood-borne factors inhibit Alzheimer's $\beta$-amyloid fibril formation in vitro. Exp Neurol. 2006;202(1):125-32.

41. Jarrett JT, Lansbury Jr PT. Seeding "one-dimensional crystallization" of amyloid: a pathogenic mechanism in Alzheimer's disease and scrapie? Cell. 1993;73(6):1055-8.

42. Ghosh P, Kumar A, Datta B, Rangachari V. Dynamics of protofibril elongation and association involved in A 42 peptide aggregation in Alzheimer's disease. BMC Bioinform. 2010;11 Suppl 6:S24.

43. Jeong JS, Ansaloni A, Mezzenga R, Lashuel HA, Dietler G. Novel mechanistic insight into the molecular basis of amyloid polymorphism and secondary nucleation during amyloid formation. J Mol Biol. 2013;425(10):1765-81.

44. Salvadores N, Shahnawaz M, Scarpini E, Tagliavini F, Soto C. Detection of misfolded $A \beta$ oligomers for sensitive biochemical diagnosis of Alzheimer's disease. Cell Rep. 2014;7(1):261-8

45. Roher AE, Esh CL, Kokjohn TA, Castaño EM, Van Vickle GD, Kalback WM, et al. Amyloid $\beta$ peptides in human plasma and tissues and their significance for Alzheimer's disease. Alzheimers Dement. 2009:5(1):18-29.

46. Arai $\mathrm{H}$, Lee VM, Messinger ML, Greenberg BD, Lowery DE, Trojanowski JQ. Expression patterns of $\beta$-amyloid precursor protein ( $\beta$-APP) in neural and nonneural human tissues from Alzheimer's disease and control subjects. Ann Neurol. 1991;30(5):686-93.

47. Clifford PM, Zarrabi S, Siu G, Kinsler KJ, Kosciuk MC, Venkataraman V, et al $A \beta$ peptides can enter the brain through a defective blood-brain barrier and bind selectively to neurons. Brain Res. 2007:1142:223-36.

48. Cho SM, Kim HV, Lee S, Kim HY, Kim W, Kim TS, et al. Correlations of amyloid- $\beta$ concentrations between CSF and plasma in acute Alzheimer mouse model. Sci Rep. 2014;4:6777. 